\title{
Cepharanthine hydrochloride reverses P-glycoprotein-mediated multidrug resistance in human ovarian carcinoma A2780/Taxol cells by inhibiting the PI3K/Akt signaling pathway
}

\author{
CHEN-ZHENG HUANG ${ }^{1-3^{*}}$, YA-FENG WANG ${ }^{2 *}$, YAN ZHANG $^{3}$, YOU-MEI PENG ${ }^{3}$, \\ YI-XIAN LIU ${ }^{3}$, FANG MA ${ }^{3}$, JIN-HUA JIANG ${ }^{3}$ and QING-DUAN WANG ${ }^{3}$ \\ ${ }^{1}$ School of Pharmaceutical Sciences, Zhengzhou University; ${ }^{2}$ Department of Pharmacology, School of Medicine, \\ Zhengzhou University, Zhengzhou, Henan 450001; ${ }^{3}$ Academy of Medical and Pharmaceutical Sciences, \\ Zhengzhou University, Zhengzhou, Henan 450052, P.R. China
}

Received January 21, 2017; Accepted June 12, 2017

DOI: 10.3892/or.2017.5879

\begin{abstract}
Ovarian cancer has the highest mortality rate among gynecologic malignant tumors. The major obstacle to treatment success is multidrug resistance (MDR) to chemotherapy drugs. Cepharanthine hydrochloride $(\mathrm{CH})$, a natural alkaloidderived compound, has shown MDR reversal potency in several tumor cell lines; however, the molecular mechanism is not entirely known. In the present study, we assessed whether $\mathrm{CH}$ sensitized malignant cells to chemotherapy drugs in ovarian cancer and explored the relevant mechanism. We found that $\mathrm{CH}$ reduced the $\mathrm{IC}_{50}$ value of paclitaxel and increased intracellular rhodamine-123 accumulation in human ovarian cancer A2780/Taxol cells in a concentration-dependent manner. Reverse transcription polymerase chain reaction and western blot assay demonstrated that $\mathrm{CH}$ inhibited $M D R 1$ expression as indicated by reduced mRNA and protein levels in A2780/ Taxol cells. In addition, the inhibitory effect was strengthened after $\mathrm{CH}$ was combined with the specific PI3K/Akt signaling pathway inhibitor LY294002. Furthermore, p-Akt expression decreased gradually with the concentration of $\mathrm{CH}(2,4$ and $8 \mu \mathrm{M}$ ). Taken together, these findings indicated that $\mathrm{CH}$ reversed P-glycoprotein-mediated MDR in A2780/Taxol cells by inhibiting the PI3K/Akt signaling pathway.
\end{abstract}

\section{Introduction}

Ovarian cancer has the highest mortality rate among gynecologic malignant tumors and is the fifth leading cause of cancer

Correspondence to: Professor Qing-Duan Wang, Academy of Medical and Pharmaceutical Sciences, Zhengzhou University, 40 Daxue Road, Zhengzhou, Henan 450052, P.R. China

E-mail: wangqd@zzu.edu.cn

*Contributed equally

Key words: cepharanthine hydrochloride, multidrug resistance, P-gp, ovarian cancer, PI3K/Akt signaling pathway death in women worldwide (1). Patients with ovarian cancer are treated with standard therapy, including debulking surgery and platinum and taxane-based chemotherapy, but have a low 5 -year relative survival rate of $<45 \%$, according to the latest statistics (2). The major obstacle to treatment success is the development of multidrug resistance (MDR) (3).

MDR occurs when malignant tumors become resistant to one type of anticancer drug and acquire simultaneous resistance to different drugs with different chemical structures and modes of action. The most common mechanism of MDR is the overexpression of ATP-binding cassette (ABC) transporters, a protein family of efflux pumps on cell membranes. These transporters have a drug-binding site that is able to change conformation to recognize and catalyze the efflux of diverse substrates from cells $(4,5)$. Among them, P-glycoprotein (P-gp), encoded by the $M D R l$ gene, extrudes chemotherapeutic drugs out of cancer cells and plays an important role in the drug resistance of human cancers.

$M D R 1 / \mathrm{P}-g$ pexpression, which has been studied in numerous malignant cells, including human ovarian tumors $(6,7)$, is mediated through various pathways, including the extracellular signal-regulated kinase (ERK) (8), c-Jun NH2-terminal kinase (JNK) (9), nuclear factor $\kappa$-light-chain-enhancer of activated B cells (NF- $\kappa$ B) (10), and phosphoinositide 3-kinase (PI3K)/ Akt pathways (11). Among these, PI3K/Akt, a well-studied signal transduction pathway related to apoptosis, was recently reported to be involved in reversing solid tumor MDR (12). Consequently, the PI3K/Akt signaling pathway could become a new therapeutic target for reversing drug resistance in ovarian cancer.

Because they are more potent and less toxic than previous MDR reversal agents, natural extracts have been evaluated for the discovery of novel MDR reversing agents (13). We evaluated cepharanthine hydrochloride $(\mathrm{CH})$, a natural alkaloid-derived reversal agent produced by salification from cepharanthine. Cepharanthine, extracted from Stephania cepharantha Hayata (14), was reported to reverse MDR primarily through the suppression of $\mathrm{P}-\mathrm{gp}$ function and expression in certain MDR tumor cells $(15,16)$. This result was similar to that of our previous study on leukemia $(9,17,18)$. However, to the best of 
our knowledge, there is no data concerning the ability of $\mathrm{CH}$ to reverse MDR in an ovarian cancer cell line or the evaluation of its regulatory mechanism. In the present study, we assessed whether $\mathrm{CH}$ improved tumor sensitivity to chemotherapeutics in ovarian malignancy following our preview study regarding signaling pathways (9). In addition, we sequentially explored the regulation of the relevant signal transduction.

\section{Materials and methods}

Cell lines and cell culture. The human ovarian cancer cell line, A2780 (paclitaxel-sensitive), and its paclitaxel-resistant counterpart, A2780/Taxol, were purchased from KeyGen Biotech (Jiangsu, China). A2780 and A2780/Taxol cells were maintained in RPMI-1640 cell culture medium (Solarbio Science and Technology Co., Ltd., Beijing, China) supplemented with $10 \%$ heat-inactivated fetal bovine serum (Gibco, NY, USA) and 1\% penicillin-streptomycin $(100 \mathrm{U} / \mathrm{ml}$ penicillin $\mathrm{G}$ and $100 \mathrm{mg} / \mathrm{ml}$ streptomycin) in a $5 \% \mathrm{CO}_{2}$ humidified atmosphere at $37^{\circ} \mathrm{C}$. A2780/Taxol cells were routinely cultured in the presence of $800 \mathrm{ng} / \mathrm{ml}$ paclitaxel after chronic exposure to paclitaxel and grew in the drug-free medium for two weeks before the study.

Determination of MDR in A2780/Taxol cells. To determine MDR and calculate the resistant index (RI), chemosensitivity of A2780/Taxol and the parental A2780 cells to paclitaxel was measured using an MTT assay [3-(4,5-dimethylthiazol2-yl)-2,5-diphenyl tetrazolium bromide; Sigma, St. Louis, MO, USA]. A2780/Taxol and A2780 cells in exponential growth were seeded in a 96-well plate at a density of $5 \times 10^{3}$ cells per well, and incubated overnight. Four parallel wells were treated with various concentrations of paclitaxel diluted with culture medium. After $72 \mathrm{~h}$ of incubation, $20 \mu \mathrm{l}$ of MTT was added to each well and the cells were further cultured for $4 \mathrm{~h}$. The medium was carefully removed and $150 \mu \mathrm{l}$ of dimethylsulfoxide was added to each well to dissolve the dark blue formazan crystals. The absorbance at a wavelength of $570 \mathrm{~nm}$ was measured using a Bio-Rad ELISA plate reader (Bio-Rad, Hercules, CA, USA). All the experiments were repeated independently at least three times. The concentrations resulting in $50 \%$ inhibition of cell growth ( $\mathrm{IC}_{50}$ values) for paclitaxel were calculated using GraphPad Prism 6.0 (GraphPad Software, Inc., La Jolla, CA, USA). The resistant index (RI) values were calculated using the following formula: $\mathrm{RI}=\left(\mathrm{IC}_{50}\right.$ of $\mathrm{A} 2780 /$ Taxol cells) / ( $\mathrm{IC}_{50}$ of A2780 cells).

Reversal efficacy assay. The ability of $\mathrm{CH}$ to reverse MDR was evaluated in A2780/Taxol cells using the MTT assay. Briefly, after A2780/Taxol cells were seeded in a 96-well plate $\left(5 \times 10^{3}\right.$ cells/well) and cultured overnight, multiple concentrations of paclitaxel alone or in combination with $\mathrm{CH}(2,4$ and $8 \mu \mathrm{M})$ were added to each group of four parallel wells for an additional $72 \mathrm{~h}$. MTT was added and maintained for $4 \mathrm{~h}$, then the absorbance of each well was detected using the Bio-Rad ELISA plate reader. The reversal fold (RF) values were calculated using the following formula: $\mathrm{RF}=\left(\mathrm{IC}_{50}\right.$ of paclitaxel alone) / ( $\mathrm{IC}_{50}$ of paclitaxel in combination with $\left.\mathrm{CH}\right)$.

Rhodamine-123 accumulation assay. The effect of $\mathrm{CH}$ on the transport function of $\mathrm{P}-\mathrm{gp}$ was detected using a rhoda-
Table I. Cytotoxicity of paclitaxel in A2780/Taxol and A2780 cells by MTT assay.

\begin{tabular}{llll}
\hline & \multicolumn{2}{c}{$\mathrm{IC}_{50}(\mathrm{ng} / \mathrm{ml})$} & \\
\cline { 2 - 3 } Drug & $\mathrm{A} 2780 /$ Taxol & A2780 & Resistant index (RI) \\
\hline Paclitaxel & $1475.0 \pm 22.6^{\mathrm{a}}$ & $39.5 \pm 2.8$ & 37.3 \\
\hline${ }^{\mathrm{a} p<0.01 \text { vs. A2780. }}$ & \\
\hline
\end{tabular}

Table II. Effect of $\mathrm{CH}$ on the cytotoxicity of paclitaxel in A2780/Taxol cells by MTT assay.

\begin{tabular}{lcc}
\hline Drug and concentrations & $\mathrm{IC}_{50}(\mathrm{ng} / \mathrm{ml})$ & Reversal fold (RF) \\
\hline Paclitaxel alone & $1475.0 \pm 22.6$ & \\
Paclitaxel $+2 \mu \mathrm{M} \mathrm{CH}$ & $688.0 \pm 7.9^{\mathrm{a}}$ & 2.1 \\
Paclitaxel $+4 \mu \mathrm{M} \mathrm{CH}$ & $478.3 \pm 9.6^{\mathrm{a}}$ & 3.1 \\
Paclitaxel $+8 \mu \mathrm{M} \mathrm{CH}$ & $185.7 \pm 6.5^{\mathrm{a}}$ & 7.9
\end{tabular}

A2780/Taxol cells were treated with paclitaxel alone or in combination with different concentrations of $\mathrm{CH}$ for $72 \mathrm{~h}$. ${ }^{\mathrm{a}} \mathrm{p}<0.01 \mathrm{vs}$. paclitaxel alone.

mine-123 (Rho-123, Sigma) accumulation assay. A2780/Taxol and A2780 cells were seeded in 12-well plates at a density of $4 \times 10^{5}$ cells per well and cultured overnight. The cells were treated with $\mathrm{CH}(2,4$ and $8 \mu \mathrm{M})$ for $2 \mathrm{~h}$, then incubated with Rho-123 (final concentration of $1 \mu \mathrm{g} / \mathrm{ml}$ ) for $1 \mathrm{~h}$. To terminate the exclusion of Rho-123, ice-cold phosphate buffered saline (PBS, pH 7.4) was used to wash the harvested and collected cells twice. The intracellular drug fluorescence was measured using a flow cytometer (Beckman Coulter, Fullerton, CA, USA) and analyzed using Expo32 ADC software (Beckman Coulter).

Reverse transcriptase-quantitative real-time PCR. The effect of $\mathrm{CH}$ on MDR1 mRNA expression in A2780/Taxol cells was determined using reverse transcriptase-quantitative real-time PCR (RT-qPCR) analysis. A2780/Taxol cells $\left(1 \times 10^{5} / \mathrm{ml}\right)$ in exponential growth were incubated with different concentrations $(2,4$ and $8 \mu \mathrm{M})$ of $\mathrm{CH}$ for $48 \mathrm{~h}$. Total RNA was extracted using RNAiso Plus (Takara Bio Inc., Dalian, China) in a laminar flow hood, following the manufacturer's protocol. Reverse transcription into cDNA was carried out using a PrimeScript $^{\mathrm{TM}}$ RT reagent kit (Takara). The real-time PCR reaction was performed with $\mathrm{SYBR}^{\circledR}$ Premix Ex Taq ${ }^{\mathrm{TM}}$ II (Takara). The primers used for PCR amplification of $M D R 1$ and the housekeeping gene, GAPDH, were as follows: $M D R 1$ forward, 5'-CTG CTT GAT GGC AAA GAA ATA AAG-3'; reverse, 5'-GGC TGT TGT CTC CAT AGG CAA T-3'. GAPDH forward, 5'-CAG GAG GCA TTG CTG ATG AT-3'; reverse, 5'-GAA GGC TGG GGC TCA TTT-3'. The PCR conditions included three stages: stage 1 was an initial denaturation $\left(95^{\circ} \mathrm{C}\right.$ for $30 \mathrm{sec})$, stage 2 was 40 cycles of PCR $\left(95^{\circ} \mathrm{C}\right.$ for $5 \mathrm{sec}$ and $60^{\circ} \mathrm{C}$ for $30 \mathrm{sec}$ ), and stage 3 was melt curve analysis. The 


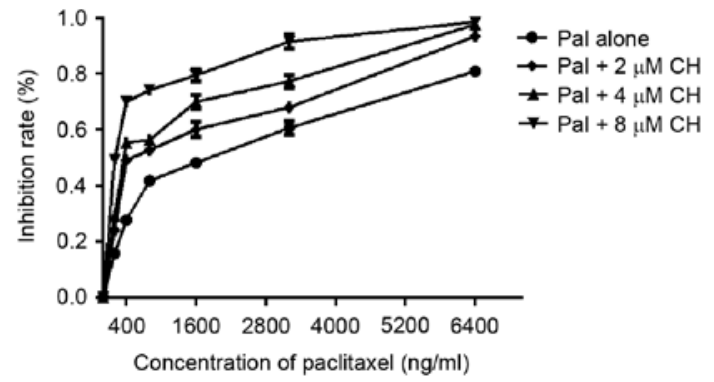

Figure 1. Effect of $\mathrm{CH}$ on paclitaxel-induced cytotoxicity. A2780/Taxol cells were treated with various concentrations paclitaxel in combination with $\mathrm{CH}$ $(2,4$ and $8 \mu \mathrm{M})$ for $72 \mathrm{~h}$. Proliferation of A2780/Taxol cells was determined using an MTT assay and the inhibition rate (\%) was calculated. Data are expressed as mean $\pm \mathrm{SD}$ of triplicate experiments.

comparative $\mathrm{Ct}\left(2^{-\Delta \Delta \mathrm{CT}}\right)$ method (19) was used to calculate the mRNA relative abundance of $M D R I$ compared with $G A P D H$.

Western blot assay. To further study the effects of $\mathrm{CH}$ on the P-gp and JNK signaling pathway at the protein level, a western blot assay was performed to detect the expression of P-gp and phospho-JNK in A2780/Taxol cells. LY294002 (Cell Signaling, Beverly, MA, USA) was used to specifically inhibit the PI3K/Akt signaling pathway during this process. In brief, after A2780/Taxol cells were treated with $\mathrm{CH}(2,4$ and $8 \mu \mathrm{M})$ in the presence or absence of LY294002 for $48 \mathrm{~h}$, total protein from A2780 cells without treatment and A2780/Taxol cells with treatment were extracted using radioimmunoprecipitation assay (RIPA) buffer (Takara). The proteins were then fractionated using sodium dodecyl sulfate polyacrylamide gel electrophoresis (SDS-PAGE, Beyotime Biotechnology, Jiangsu, China). The proteins of interest were excised from the gel and transferred onto polyvinylidene difluoride membranes.
Relative protein concentration was assessed by immunoblotting using P-gp antibody (ab170904, Abcam, Cambridge, UK), total-Akt (t-Akt) antibody (\#9272, Cell Signaling), and phospho-Akt (p-Akt, Ser473) antibody (\#9271, Cell Signaling). GAPDH (10494-1-AP, Proteintech, Rosemont, IL, USA) was used as a loading control.

Statistical analysis. All the experiments were carried out independently at least three times. The data were expressed as mean \pm standard deviation (SD) and analyzed using GraphPad Prism 6.0 (GraphPad Software, Inc.). One-way analysis of variance (ANOVA) was used to measure statistical significance among treatment groups and $\mathrm{p}<0.05$ was considered statistically significant.

\section{Results}

Determination of MDR of A2780/Taxol cells. To determine the MDR of A2780/Taxol cells, we treated A2780/Taxol and A2780 cells with different concentrations of paclitaxel to calculate the $\mathrm{IC}_{50}$. As shown in Table I, the $\mathrm{IC}_{50}$ of A2780/Taxol increased significantly compared the parental cells $(1475.0 \mathrm{ng} / \mathrm{ml} \mathrm{vs}$. $39.5 \mathrm{ng} / \mathrm{ml}, \mathrm{p}<0.01)$ and the RI value was 37.3. These data confirmed the MDR of A2780/Taxol cells.

Effect of $\mathrm{CH}$ on reversing $M D R$. To evaluate whether $\mathrm{CH}$ influenced the effects of paclitaxel, A2780/Taxol cells were treated with paclitaxel alone or in combination with different concentrations of $\mathrm{CH}(2,4$ and $8 \mu \mathrm{M})$ for $72 \mathrm{~h}$. Combination treatment significantly decreased the $\mathrm{IC}_{50}$ values of paclitaxel. The $\mathrm{IC}_{50}$ values and $\mathrm{RF}$ results are presented in Table II. Furthermore, the reversal effect of $\mathrm{CH}$ was dose-dependent, as indicated in Fig. 1. These data suggested that $\mathrm{CH}$ reversed the MDR of A2780/Taxol cells.
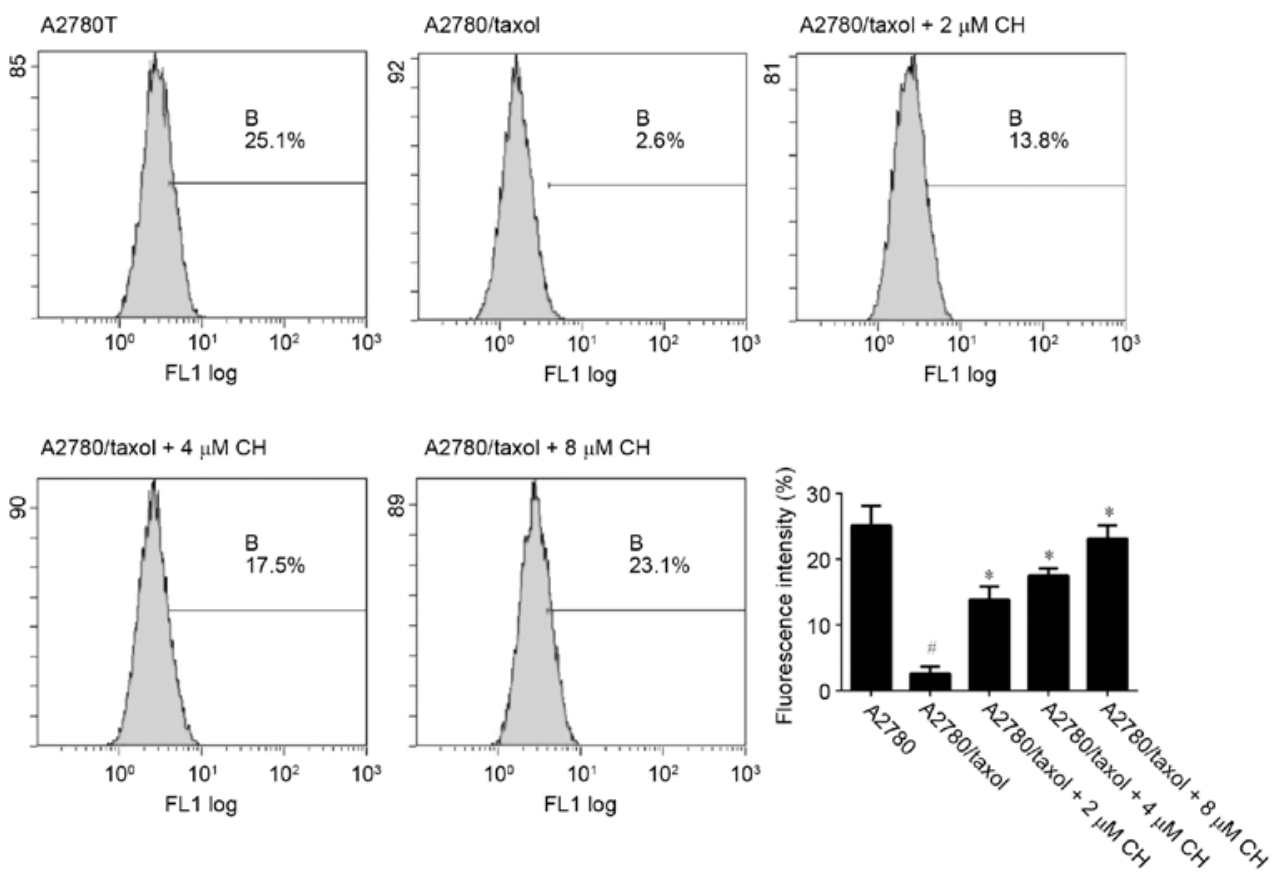

Figure 2. Effect of $\mathrm{CH}$ on intracellular Rho-123 accumulation in A2780 and A2780/Taxol cells. A2780/Taxol cells were treated with different concentrations of CH. A2780 and A2780/Taxol cells without treatment were set as the control, respectively. Rho-123 fluorescence intensity was detected using a flow cytometer and expressed as mean \pm SD. ${ }^{\#}$ p $<0.01$ vs. A2780. ${ }^{*}$ p $<0.05$ vs. A2780/Taxol. 


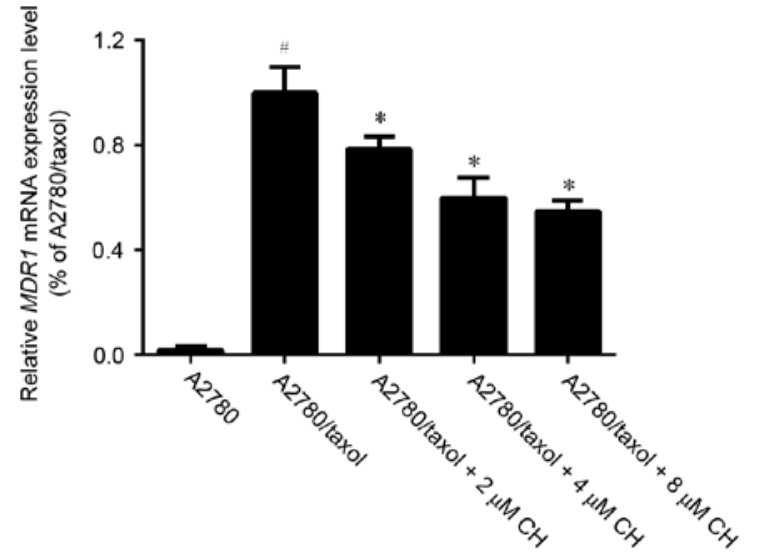

Figure 3. Effect of $\mathrm{CH}$ on MDR1 mRNA expression by RT-qPCR assay in A2780 and A2780/Taxol cells. A2780/Taxol cells were treated with different concentrations of $\mathrm{CH} .{ }^{*} \mathrm{p}<0.01$ vs. A2780. ${ }^{*} \mathrm{p}<0.05$ vs. A2780/Taxol.
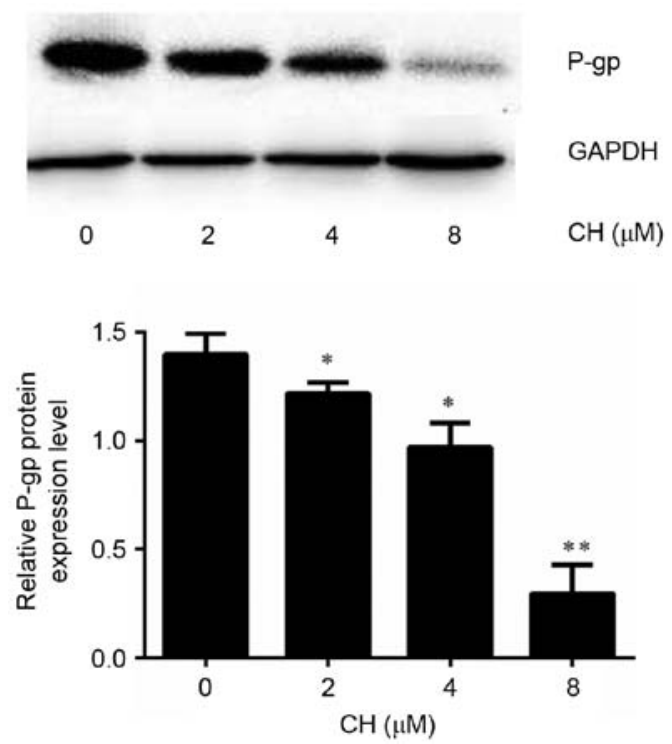

Figure 4. Effect of $\mathrm{CH}$ on P-gp expression as indicated by western blot assay in A2780/Taxol cells. A2780/Taxol cells were treated with different concentrations of $\mathrm{CH}$ for $48 \mathrm{~h}$. Data were expressed as mean $\pm \mathrm{SD}$, and GAPDH was the loading control. ${ }^{*} \mathrm{p}<0.05,{ }^{* *} \mathrm{p}<0.01 \mathrm{vs.}$ A2780/Taxol without treatment.

Effect of $\mathrm{CH}$ on intracellular Rho-123 accumulation. Rho-123, a specific substrate for P-gp, emits yellow-green fluorescence, which can be detected by flow cytometry to indicate the transport capacity of P-gp. As shown in Fig. 2, the intracellular Rho-123 fluorescence in A2780 cells was significantly higher than that in A2780/Taxol cells (25.1 vs. $2.6 \%, \mathrm{p}<0.01)$ in the untreated state. After A2780/Taxol cells were exposed to various concentrations of $\mathrm{CH}(2,4$ and $8 \mu \mathrm{M})$, intracellular fluorescence intensity increased significantly in a dose-dependent manner $(\mathrm{p}<0.05)$.

Effect of $C H$ on the expression of MDRI $m R N A$ and protein. To observe whether $\mathrm{CH}$ affected the expression of MDRl, we detected MDR1 mRNA using RT-qPCR in A2780 and A2780/Taxol cells that were incubated with different concentrations of $\mathrm{CH}$. The results indicated that the level of MDRI mRNA in A2780/Taxol cells was far higher than that in A2780
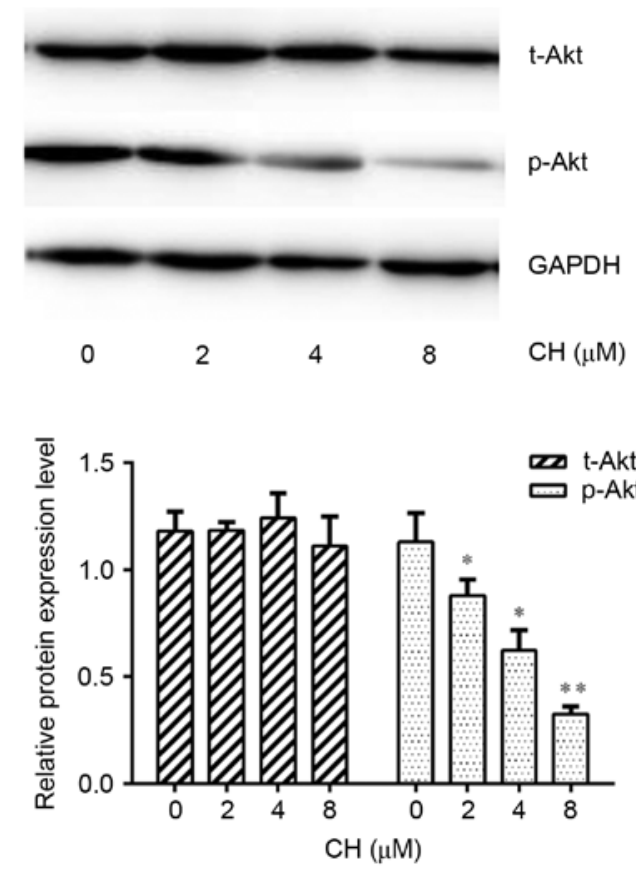

Figure 5. Effect of $\mathrm{CH}$ on the expression of t-Akt and p-Akt as indicated by western blot assay in A2780/Taxol cells. A2780/Taxol cells were treated with different concentrations of $\mathrm{CH}$ for $48 \mathrm{~h}$. Data are expressed as mean $\pm \mathrm{SD}$ and GAPDH was the loading control. ${ }^{*} \mathrm{p}<0.05,{ }^{* *} \mathrm{p}<0.01$ vs. A2780/Taxol without treatment.

cells. In addition, the expression of MDR1 mRNA decreased significantly in a dose-dependent manner after treatment with different concentrations of $\mathrm{CH}$ (Fig. 3). We further assessed the P-gp level in A2780 cells and A2780/Taxol cells using a western blot assay. The results indicated that the P-gp level in A2780/Taxol cells was significantly higher than that in A2780 cells and decreased sharply after treatment with CH (Fig. 4).

Effect of $\mathrm{CH}$ on the PI3K/Akt pathway. To further reveal the mechanisms by which $\mathrm{CH}$ inhibited P-gp expression in ovarian cancer, A2780/Taxol cells were exposed to various concentrations of $\mathrm{CH}$ for $48 \mathrm{~h}$. Endogenous t-Akt and p-Akt (Ser473), the most important modulators of the PI3K/Akt signaling pathway, were detected using a western blot assay. The results indicated that $\mathrm{p}$-Akt expression was suppressed by $\mathrm{CH}$ in a concentration-dependent manner (Fig. 5). It is noteworthy that the P-gp inhibitory effect of $\mathrm{CH}$ was enhanced when combined with the specific PI3K/Akt signaling pathway inhibitor, LY294002 (Fig. 6).

\section{Discussion}

According to the latest world cancer report announced by WHO in 2014, cancer will continue to be the leading cause of death over the next 100 years. Although cancer therapy has made significant progress with the improvement of medicine, chemotherapy resistance is still a major challenge. The data indicate that $>90 \%$ of cancer-related deaths are associated with MDR, which is characterized by the overexpression of $\mathrm{ABC}$ transporters (20). Fifteen of a total of $49 \mathrm{ABC}$ proteins confirmed in the human genome (21) were reported to export chemotherapeutic drugs (22). Nevertheless, only three impor- 

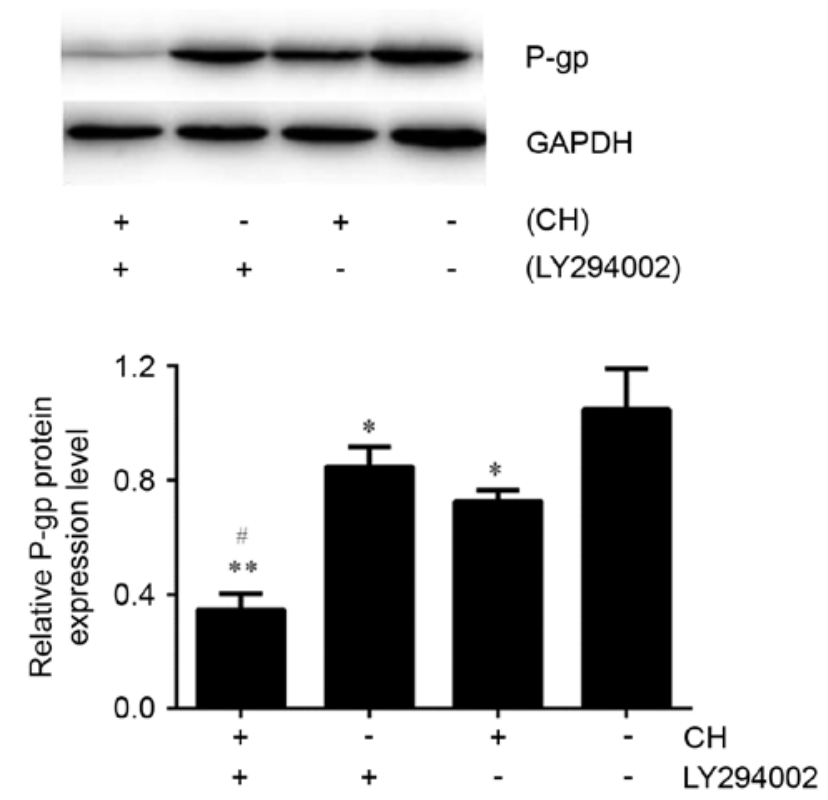

Figure 6. Effects of $\mathrm{CH}$ on the specific PI3K/Akt signaling pathway inhibitor LY294002. The downregulation of P-gp expression was induced as indicated by western blot assay in A2780/Taxol cells. CH-induced downregulation of P-gp expression was strengthened when CH was combined with LY294002. Data were expressed as mean $\pm \mathrm{SD}$, and GAPDH was the loading control ${ }^{*} \mathrm{p}<0.05,{ }^{* *} \mathrm{p}<0.01 \mathrm{vs} . \mathrm{A} 2780 /$ Taxol without treatment. ${ }^{\#} \mathrm{p}<0.05$ vs. A2780/ Taxol treated with CH or LY294002 alone.

tant transporters have been identified as primary contributors to MDR in cancer: P-gp (MDR1; ABCB1), multidrug resistance associated protein 1 (MRP1; ABCC1), and breast cancer resistance protein (BCRP; ABCG2) (23).

$\mathrm{P}$-gp, the first human $\mathrm{ABC}$ protein studied in the past three decades, is a classical pathway of drug resistance. Because of its important role in MDR, the synthesis and development of $\mathrm{P}$-gp inhibitors are promising for reversing MDR mediated by P-gp. These inhibitors can suppress the pump function of P-gp or lower the expression level of MDR1, which reduces drug efflux and increases the intracellular accumulation of chemotherapy drugs, thereby achieving a reversal effect (24). In general, P-gp inhibitors are classified into three generations (25). The first-generation P-gp inhibitors are substrates of P-gp and have been used in clinical practice for other purposes. These include verapamil, nifedipine, quinidine, and cyclosporine A. The first-generation drugs reverse MDR at concentrations far higher than those resulting from conventional dosing and, therefore, their use leads to unacceptable side effects (26). Through structural modification of the first-generation inhibitors, researchers developed the secondgeneration P-gp inhibitors, represented by dexverapamil (R-enantiomer of verapamil) and PSC833 (derivative of cyclosporine A) $(27,28)$. These drugs have higher affinity for P-gp and lower toxicity. However, the second-generation inhibitors are substrates of cytochrome P450 and can interfere with the pharmacokinetics of chemotherapeutic drugs. Therefore, they are greatly restricted in clinical application. The third-generation P-gp inhibitors, represented by tariquidar (XR9576) and zosuquidar (LY335979), have high potency and low toxicity and are not substrates of cytochrome P450 (29). Nevertheless, a series of clinical trials did not show much promise for their use in cancer treatment (30). So far, none of the three generations of synthetic inhibitors have been approved for clinical application, which has led researchers to focus their attention on natural extracts to seek new reversal agents.

Cepharanthine, a natural alkaloid extracted from S. cepharantha Hayata (14), has been used to treat bronchial asthma, snake venom-induced hemolysis, and allergic inflammation in Japan (31). In recent years, $\mathrm{CH}$ has attracted additional attention owing to its broad spectrum of biological properties, including anti-inflammatory, antiviral, and anti-allergic activities and, particularly, its various pharmacological effects in cancer treatment $(32,33)$. Some cancer research has indicated that $\mathrm{CH}$ exerted its antitumor activity in different carcinomas $(34,35)$ and triggered apoptosis in a human hepatocellular carcinoma cell line (31) and leukemia cell line (36). Moreover, precursor studies verified that $\mathrm{CH}$ potently enhanced the sensitivity of anticancer agents and inhibited P-gp in human bladder cancer cells (37), chronic myelogenous leukemia cells $(9,38)$, hepatocellular carcinoma (15), and cholangiocarcinoma (34). Similar results have also been obtained by our group in a study of the ability of $\mathrm{CH}$ to reverse MDR in K562/ADR cells (9). Nevertheless, the specific regulatory mechanism of $\mathrm{CH}$ is still not clear. In the present study, we focused primarily on whether $\mathrm{CH}$ reversed P-gp-mediated MDR in human ovarian cancer and its mechanism of action.

Ovarian cancer is the most lethal gynecological cancer and treatment often fails because of MDR to chemotherapy. Therefore, identification of potent and low toxic inhibitors is necessary. To determinate the MDR reversing effect of $\mathrm{CH}$ in ovarian cancer, we treated drug-resistant A2780/Taxol cells with paclitaxel alone or in combination with $\mathrm{CH}$. The results indicated that $\mathrm{IC}_{50}$ values decreased dramatically in a concentration-dependent manner after $\mathrm{CH}$ was co-incubated with paclitaxel (Fig. 1). The RF reached 7.9 (Table II), which indicated that $\mathrm{CH}$ enhanced the sensitivity of A2780/Taxol cells to the chemotherapy drug and reversed drug resistance. Moreover, to estimate the P-gp inhibition of $\mathrm{CH}$, a Rho-123 accumulation assay was performed in A2780/Taxol and parental cell lines. The flow cytometric data indicated that $\mathrm{CH}$ significantly increased intracellular accumulation of the P-gp substrate, Rho-123, in a dose-dependent manner (Fig. 2). In addition, the P-gp inhibitory effect of $\mathrm{CH}$ was confirmed by the suppression of $M D R 1$ mRNA and protein expression in A2780/Taxol cells after treatment with CH (Figs. 3 and 4).

To further reveal the mechanisms by which $\mathrm{CH}$ inhibited P-gp in ovarian cancer, we explored the relationship between the reversal effect and relevant signal transduction. The PI3K/Akt signaling pathway is an important intracellular signal transduction pathway that participates in numerous physiological and pathological processes, particularly controlling survival and apoptosis (39). In recent years, joint drug studies suggested that inhibition of the PI3K/Akt signaling pathway downregulated MDR1 expression and overcame P-gp-mediated MDR in human myelogenous leukemia (40), gastric cancer (12), and hepatocellular carcinoma (41). During this process, Akt played a critical role. In this study, we found that $\mathrm{p}$-Akt expression was inhibited by $\mathrm{CH}$ in a concentrationdependent manner, whereas t-Akt expression remained the same (Fig. 5). Combined with previous results, we suggest that $\mathrm{CH}$ reduced $\mathrm{P}$-gp expression by inhibiting the PI3K/Akt 
pathway. To confirm this view, we simultaneously treated A2780/Taxol cells with CH and LY294002, a specific PI3K/ Akt signaling pathway inhibitor, and found that the P-gp inhibitory effect of $\mathrm{CH}$ was dramatically enhanced (Fig. 6). This further indicated that $\mathrm{CH}$ downregulated $\mathrm{P}$-gp expression in human ovarian carcinoma cells by inhibiting the PI3K/Akt pathway.

In conclusion, this study demonstrated that $\mathrm{CH}$ reversed P-gp-mediated MDR in A2780/Taxol cells. In addition, the mechanism of $\mathrm{CH}$-induced MDR-reversion in human ovarian cancer may have involved the inhibition of the PI3K/Akt signaling pathway, which may contribute to further investigation into potential clinical application of $\mathrm{CH}$ in ovarian cancer treatment.

\section{Acknowledgements}

This study was supported by National Natural Science Foundation of China (no. 81302813) and Major Social Welfare Projects for Scientific Research of Henan Province of China (no. 081100912400).

\section{References}

1. Siegel RL, Miller KD and Jemal A: Cancer statistics, 2016. CA Cancer J Clin 66: 7-30, 2016.

2. Webb PM and Jordan SJ: Epidemiology of epithelial ovarian cancer. Best Pract Res Clin Obstet Gynaecol 41: 3-14, 2017.

3. Zahreddine $\mathrm{H}$ and Borden KL: Mechanisms and insights into drug resistance in cancer. Front Pharmacol 4: 28, 2013.

4. Gottesman MM: Mechanisms of cancer drug resistance. Annu Rev Med 53: 615-627, 2002.

5. Gillet JP and Gottesman MM: Mechanisms of multidrug resistance in cancer. Methods Mol Biol 596: 47-76, 2010.

6. Zhang H, Wang J, Cai K, Jiang L, Zhou D, Yang C, Chen J, Chen D and Dou J: Downregulation of gene MDR1 by shRNA to reverse multidrug-resistance of ovarian cancer A2780 cells. J Cancer Res Ther 8: 226-231, 2012.

7. Li Z, Hu S, Wang J, Cai J, Xiao L, Yu L and Wang Z: MiR-27a modulates MDR1/P-glycoprotein expression by targeting HIPK2 in human ovarian cancer cells. Gynecol Oncol 119: 125-130, 2010.

8. Zhao BX, Sun YB, Wang SQ, Duan L, Huo QL, Ren F and Li GF: Grape seed procyanidin reversal of P-glycoprotein associated multi-drug resistance via down-regulation of $\mathrm{NF}-\kappa \mathrm{B}$ and MAPK/ERK mediated YB-1 activity in A2780/T cells. PLoS One 8: e71071, 2013.

9. Han L, Wang Y, Guo X, Zhou Y, Zhang J, Wang N, Jiang J, Ma F and Wang Q: Downregulation of MDR1 gene by cepharanthine hydrochloride is related to the activation of c-Jun/JNK in K562/ ADR cells. BioMed Res Int 2014: 164391, 2014.

10. O'Neill AJ, Prencipe M, Dowling C, Fan Y, Mulrane L, Gallagher WM, O'Connor D, O'Connor R, Devery A, Corcoran C, et al: Characterisation and manipulation of docetaxel resistant prostate cancer cell lines. Mol Cancer 10: 126, 2011.

11. Misra S, Ghatak S and Toole BP: Regulation of MDR1 expression and drug resistance by a positive feedback loop involving hyaluronan, phosphoinositide 3-kinase, and ErbB2. J Biol Chem 280: 20310-20315, 2005.

12. Mao Z, Zhou J, Luan J, Sheng W, Shen X and Dong X: Tamoxifen reduces P-gp-mediated multidrug resistance via inhibiting the $\mathrm{PI} 3 \mathrm{~K} / \mathrm{Akt}$ signaling pathway in ER-negative human gastric cancer cells. Biomed Pharmacother 68: 179-183, 2014.

13. Deferme S, Van Gelder J and Augustijns P: Inhibitory effect of fruit extracts on P-glycoprotein-related efflux carriers: An in-vitro screening. J Pharm Pharmacol 54: 1213-1219, 2002.

14. Tomita M, Fujitani K and Aoyagi Y: Synthesis of dl-cepharanthine. Tetrahedron Lett 13: 1201-1206, 1967.

15. Nakajima A, Yamamoto Y, Taura K, Hata K, Fukumoto M, Uchinami H, Yonezawa $\mathrm{K}$ and Yamaoka Y: Beneficial effect of cepharanthine on overcoming drug-resistance of hepatocellular carcinoma. Int J Oncol 24: 635-645, 2004.
16. Ikeda R, Che XF, Yamaguchi T, Ushiyama M, Zheng CL, Okumura H, Takeda Y, Shibayama Y, Nakamura K, Jeung HC, et al: Cepharanthine potently enhances the sensitivity of anticancer agents in K562 cells. Cancer Sci 96: 372-376, 2005.

17. Li H, Yan Z, Ning W, Xiao-Juan G, Cai-Hong Z, Jin-Hua J, Fang $M$ and Qing-Duan W: Using rhodamine 123 accumulation in CD8 cells as a surrogate indicator to study the P-glycoprotein modulating effect of cepharanthine hydrochloride in vivo. J Biomed Biotechnol 2011: 281651, 2011.

18. Peng YM, Wang N, Wang YF, Han L, Zhang Y, Jiang JH, Zhou YB and Wang QD: Correlation between reversing effect of cepharanthine hydrochloride on multidrug resistance and P-glycoprotein expression and function of K562/ADR cells. Yao Xue Xue Bao 47: 594-599, 2012 (In Chinese).

19. Schmittgen TD and Livak KJ: Analyzing real-time PCR data by the comparative C(T) method. Nat Protoc 3: 1101-1108, 2008

20. Goldman B: Multidrug resistance: Can new drugs help chemotherapy score against cancer? J Natl Cancer Inst 95: 255-257, 2003.

21. Dean M, Rzhetsky A and Allikmets R: The human ATP-binding cassette $(\mathrm{ABC})$ transporter superfamily. Genome Res 11: 1156-1166, 2001

22. Schinkel AH and Jonker JW: Mammalian drug efflux transporters of the ATP binding cassette (ABC) family: An overview. Adv Drug Deliv Rev 55: 3-29, 2003.

23. Eckford PDW and Sharom FJ: ABC efflux pump-based resistance to chemotherapy drugs. Chem Rev 109: 2989-3011, 2009.

24. Binkhathlan Z and Lavasanifar A: P-glycoprotein inhibition as a therapeutic approach for overcoming multidrug resistance in cancer: Current status and future perspectives. Curr Cancer Drug Targets 13: 326-346, 2013.

25. Krishna $R$ and Mayer LD: Multidrug resistance (MDR) in cancer. Mechanisms, reversal using modulators of MDR and the role of MDR modulators in influencing the pharmacokinetics of anticancer drugs. Eur J Pharm Sci 11: 265-283, 2000.

26. Lampidis TJ, Krishan A, Planas L and Tapiero H: Reversal of intrinsic resistance to adriamycin in normal cells by verapamil. Cancer Drug Deliv 3: 251-259, 1986.

27. Alaoui-Jamali MA, Schecter RL, Rustum YM, Centurioni MG, Lehnert $S$ and Batist G: In vivo reversal of doxorubicin resistance by a new tiapamil analog Ro11-2933. J Pharmacol Exp Ther 264: 1299-1304, 1993

28. Boesch D, Muller K, Pourtier-Manzanedo A and Loor F: Restoration of daunomycin retention in multidrug-resistant P388 cells by submicromolar concentrations of SDZ PSC 833, a nonimmunosuppressive cyclosporin derivative. Exp Cell Res 196: 26-32, 1991.

29. Martin C, Berridge G, Mistry P, Higgins C, Charlton P and Callaghan R: The molecular interaction of the high affinity reversal agent XR9576 with P-glycoprotein. Br J Pharmacol 128: 403-411, 1999.

30. Abraham J, Edgerly M, Wilson R, Chen C, Rutt A, Bakke S, Robey R, Dwyer A, Goldspiel B, Balis F, et al: A phase I study of the P-glycoprotein antagonist tariquidar in combination with vinorelbine. Clin Cancer Res 15: 3574-3582, 2009.

31. Biswas KK, Tancharoen S, Sarker KP, Kawahara K, Hashiguchi T and Maruyama I: Cepharanthine triggers apoptosis in a human hepatocellular carcinoma cell line $(\mathrm{HuH}-7)$ through the activation of JNK1/2 and the downregulation of Akt. FEBS Lett 580: 703-710, 2006

32. Okamoto M, Ono M and Baba M: Suppression of cytokine production and neural cell death by the anti-inflammatory alkaloid cepharanthine: A potential agent against HIV-1 encephalopathy. Biochem Pharmacol 62: 747-753, 2001.

33. Zhou YB, Wang YF, Zhang Y, Zheng LY, Yang XA, Wang N, Jiang JH, Ma F, Yin DT, Sun CY, et al: In vitro activity of cepharanthine hydrochloride against clinical wild-type and lamivudine-resistant hepatitis B virus isolates. Eur J Pharmacol 683: 10-15, 2012.

34. Seubwai W, Vaeteewoottacharn K, Hiyoshi M, Suzu S, Puapairoj A, Wongkham C, Okada S and Wongkham S: Cepharanthine exerts antitumor activity on cholangiocarcinoma by inhibiting NF-kappaB. Cancer Sci 101: 1590-1595, 2010.

35. Asaumi J, Nishikawa K, Matsuoka H, Iwata M, Kawasaki S, Hiraki Y and Nishijima K: Direct antitumor effect of cepharanthin and combined effect with adriamycin against Ehrlich ascites tumor in mice. Anticancer Res 15: 67-70, 1995.

36. Wu J, Suzuki H, Akhand AA, Zhou YW, Hossain K and Nakashima I: Modes of activation of mitogen-activated protein kinases and their roles in cepharanthine-induced apoptosis in human leukemia cells. Cell Signal 14: 509-515, 2002. 
37. Enokida H, Gotanda T, Oku S, Imazono Y, Kubo H, Hanada T, Suzuki S, Inomata K, Kishiye T, Tahara Y, et al: Reversal of P-glycoprotein-mediated paclitaxel resistance by new synthetic isoprenoids in human bladder cancer cell line. Jpn J Cancer Res 93: 1037-1046, 2002.

38. Mukai M, Che XF, Furukawa T, Sumizawa T, Aoki S, Ren XQ, Haraguchi M, Sugimoto Y, Kobayashi M, Takamatsu H, et al: Reversal of the resistance to STI571 in human chronic myelogenous leukemia K562 cells. Cancer Sci 94: 557-563, 2003.

39. Zhao HF, Wang J and Tony To SS: The phosphatidylinositol 3-kinase/Akt and c-Jun N-terminal kinase signaling in cancer: Alliance or contradiction? (Review). Int J Oncol 47: 429-436, 2015.
40. Chen JR, Jia XH, Wang H, Yi YJ, Wang JY and Li YJ: Timosaponin A-III reverses multi-drug resistance in human chronic myelogenous leukemia K562/ADM cells via downregulation of MDR1 and MRP1 expression by inhibiting PI3K/Akt signaling pathway. Int J Oncol 48: 2063-2070, 2016.

41. Gao AM, Ke ZP, Wang JN, Yang JY, Chen SY and Chen H: Apigenin sensitizes doxorubicin-resistant hepatocellular carcinoma BEL-7402/ADM cells to doxorubicin via inhibiting PI3K/Akt/Nrf2 pathway. Carcinogenesis 34: 1806-1814, 2013. 